\title{
Iconografia Militar e Práticas do Olhar: ressonâncias na visualização matemática*
}

\section{Military Iconography and the Practice of Looking: resonance in mathematical visualization}

\author{
Cláudia Regina Flores**
}

\begin{abstract}
Resumo
Este artigo foca na análise de um modo de olhar e representar registrados em plantas de fortificações militares. As hipóteses teóricas partem de uma reflexão sobre a construção e a representação do espaço militarizado no âmbito da atividade matemática, para se compreender como a operação do olhar se tornou um olhar geometrizado e, como se criaram e usaram saberes matemáticos para representar com a técnica da perspectiva. A análise é feita em plantas militares de fortificações norte-americanas dos séculos XVII e XVIII, de acordo com os preceitos dos tratados de engenharia militar. Conclui-se que um conhecimento matemático aplicado a uma prática histórica pode ser um exercício, na formação de professores, para compreender práticas de olhar em educação matemática, assim como para desenvolver atividades de visualização no ensino e aprendizagem de matemática.

Palavras-chave: Visualização Matemática. História da Matemática. Geometrização do Olhar. Cultura Visual.

\footnotetext{
Este trabalho é parte dos resultados do Projeto de Pesquisa de Pós-Doutorado intitulado $A$ geometrização do olhar: cultura visual e visualização matemática na formação de professores, desenvolvido junto à Universidade Estadual Carolina do Norte, em Raleigh, Estados Unidos da América, com a colaboração da Professora Doutora Paola Sztajn, e com suporte financeiro da CAPES/Brasil, na modalidade Bolsa de Pós-Doutorado.

** Doutora em Educação pela Universidade Federal de Santa Catarina (UFSC). Professora do Departamento de Metodologia de Ensino e do Programa de Pós-Graduação em Educação Científica e Tecnológica da Universidade Federal de Santa Catarina (UFSC), Florianópolis, SC, Brasil. Endereço para correspondência: Servidão Laje de Pedra, 171, casa 07. Itacorubi. CEP: 88034630. Florianópolis, SC, Brasil. E-mail: crf@mbox1.ufsc.br.
} 


\begin{abstract}
This paper focuses on the analysis of one way of looking at and representing plans of military forts. Theoretical assumptions come from the reflections on the construction and representation of militarized space in mathematical activity, to understand how the operation of perception has become geometrical and how they have created and used mathematical knowledge to represent using technical perspective theory. Analysis is conducted of military plans or architectural designs of American forts in the seventeenth and eighteenth centuries, in accordance with the teachings and rules found in the treaties of military engineering. We conclude that mathematical knowledge applied to an historical practice can be an exercise, in teacher education, to understand practices of looking in mathematics education as well as to develop activities of visualization in the teaching and learning of mathematics.
\end{abstract}

Keywords: Mathematical Visualization. History of Mathematics. Geometrization of the Gaze. Visual Culture.

\title{
1 Introdução
}

O papel da imagem e da visualização para a apreensão de conhecimentos e entendimento de informações tem interessado pesquisadores em diversas áreas. Na educação matemática, por exemplo, a visualização de imagens geométricas, de conceitos matemáticos tem sido, cada vez mais, considerada essencial para o ensino e a aprendizagem da matemática (TARTRE, 1990; CAVALCA, 1998; ARCAVI, 2003; NEMIROVSKY; TIERNEY, 2004; BORBA; VILLARREAL, 2005; GARDEREN, 2006; LEIVAS, 2009; PRESMEG, 2006).

Se o tema em destaque é, portanto, a visualização matemática concentrada na atividade do olhar no ensino e na aprendizagem matemática, há, aqui, uma questão latente que emerge e volta ao debate: como olhamos e como se criaram modos de olhar e de representar aquilo que olhamos (FLORES, 2007). Voltar a esta questão significa, nesse contexto, analisar como técnicas de representação foram sendo criadas, inventadas, praticadas no âmbito da história, de tal modo a capturar e fabricar um modo de olhar: o olhar geométrico. É importante reconhecer, neste caso, que tanto olhar como representar imagens no papel têm uma história, são produtos de um processo e não são auto-evidentes. Neste artigo, parte-se do princípio de que perceber esta história permite, no mínimo, reavaliar concepções e práticas em torno da visualização na educação matemática, tomadas normalmente, por professores e educadores matemáticos, como naturalizadas, a-históricas e a-temporais. 
Assim, dando continuidade à discussão da questão de como olhamos e como se criaram modos de olhar e representar o que olhamos, propomos adentrar na história da arte militar. A análise dá-se em plantas militares de fortificações norte-americanas, dos séculos XVII e XVIII, de acordo com os preceitos dos tratados de engenharia militar. As hipóteses teóricas partem de uma reflexão sobre a construção e a representação do espaço militarizado no âmbito da atividade matemática, para compreendermos como a operação do olhar se tornou um olhar geometrizado, e, ainda, como foram criados e colocados em prática saberes matemáticos para representar com a técnica da perspectiva.

Dois pontos são considerados essenciais a este debate. $\mathrm{O}$ primeiro diz respeito ao modo de olhar. Ora, como olhar as plantas militares, os projetos arquitetônicos militares? Ou ainda, que modo de olhar se formou, o qual é necessário para ver na representação a imagem de uma realidade? Trata-se de compreender como e de onde foi possível geometrizar nosso olhar, resultando quase numa naturalização do modo de olhar e representar o espaço. Para olhar a imagem é preciso aprender a olhá-la, vê-la como uma representação constituída pela ação de nossos saberes.

O segundo ponto diz respeito ao conhecimento matemático, geométrico, que torna possível a representação do espaço. Quais cálculos matemáticos, conceitos geométricos eram necessários e exigidos do engenheiro militar para representar, no papel, a ideia de uma fortificação ideal? Como engenheiros e arquitetos militares articularam, e ensinaram por meio de tratados de engenharia militar, a fortificar uma vila, uma cidade? Para representar é preciso saber, apreender um saber que é militar - a técnica da perspectiva militar.

Este artigo está organizado em quatro seções. A primeira seção, intitulada Orientações, define os conceitos teóricos e metodológicos que orientam este estudo, bem como a justificativa do porque adentrarmos na história para compreender a visualização matemática. As duas seções seguintes, intituladas Modificações e O Pentágono, delineiam as questões do estudo, tratando, em ambas as partes, sobre como o olhar foi se geometrizando e como conhecimentos geométricos foram sendo usados no âmbito da iconografia militar. Na última seção, a título de conclusões, e intitulada Ressonâncias, reflete-se sobre a análise empreendida, apontando alguns reflexos de um modo de olhar elaborado no âmbito da história e aplicado na e à educação matemática. 


\section{Orientações}

Normalmente, as pesquisas em educação matemática, ao lidarem com as questões acerca da visualização no ensino e na aprendizagem matemática, se fundamentam na psicologia da aprendizagem, na didática, na semiótica, ou na fenomenologia. Dentre algumas destas pesquisas, a título de exemplo, citamos o trabalho de Gal e Linchevski (2010), que considera teorias sobre processos de percepção visual e sobre representações do conhecimento baseadas na percepção para explicar dificuldades encontradas no processamento figural em atividades de ensino de geometria. Borba e Villarreal (2005), que se acercam de abordagens didáticas, considerando a tecnologia como uma ferramenta poderosa para tratar da interface entre o ensino e a aprendizagem matemática e a compreensão dos processos visuais. Sáenz-Ludlow e Presmeg (2006, p. 2, tradução nossa), que defendem que "[...] o ensino-aprendizado matemática é, essencialmente, uma atividade semiótica de colaboração, mediada pelo uso, recriação, interpretação, e apropriação simultâneos de uma variedade de sistemas semióticos", e a visualização matemática é, portanto, também considerada como constituída por sistemas semióticos. Num caminho similar, pela semiótica, Duval (2006) salienta que a atividade matemática é mobilizada por registros semióticos, cuja visualização requer um trabalho cognitivo.

Contudo, o estudo acerca da visualização em matemática, neste artigo, se articula com um ponto de vista teórico e metodológico apoiado sob uma perspectiva histórica, para percebermos os mecanismos pelos quais foi possível a constituição de uma forma de olhar que se faz presente na educação matemática. Assim, a história pode ser útil para notar as práticas docentes que vão se naturalizando, de tal modo que já não são mais questionadas. Como diz Bkouche (1997), voltamos à história para retomarmos o sentido dos saberes, pois é o valor social que conduz à criação de um ensino científico, acentuando o valor de certos domínios da ciência. Mas, também, e, sobretudo, remetemos à história, aqui, para perceber práticas que fabricam, constroem, educam, formatam nosso modo de olhar em matemática.

Portanto, no âmbito da teoria e da metodologia, este artigo se orienta pelo campo da historicidade de uma cultura visual. Neste caso, procuramos refletir acerca das transformações e práticas do modo de representar em perspectiva, em particular o olhar militarizado, que gera a perspectiva militar, geométrica, cavaleira. Portanto, um campo de pesquisa de natureza reflexiva, histórico-filosófica, considerando, no entanto, um pequeno segmento da história 
e da história da perspectiva. Ao inquirir sobre o uso de um dos modos de aplicar a técnica da perspectiva geométrica, focalizando um corte do saber do século XVII e XVIII, ou seja, o saber militar que projeta na planta a arquitetura das fortificações no continente americano buscamos analisar uma peça da Arqueologia do Saber (FOUCAULT, 2000).

Neste âmbito, uma das ideias fundamentais diz respeito à história arqueológica. Logo, em se tratando de uma pesquisa arqueológica em torno de um saber, a história arqueológica procura evidenciar “[...] as práticas discursivas na medida em que dão lugar a um saber, e que esse saber assume o status e o papel de ciência" (FOUCAULT, 2000, p. 216). Então, ao invés de procurar pelas práticas discursivas na densidade histórica das ciências, no nível profundo e originário, ou no solo da experiência vivida, procuramos mostrar como a instauração de uma ciência pode ser encontrada nas modificações, no jogo das diferenças e revelações, nos desvios, defasagens, autonomias e independências, através das quais diferentes historicidades se articulam. Portanto,

A episteme não é uma forma de conhecimento, ou um tipo de racionalidade que, atravessando as ciências mais diversas, manisfestaria a unidade soberana de um sujeito, de um espírito ou de uma época; é o conjunto das relações que podem ser descobertas, para uma época dada, entre as ciências, quando estas são analisadas no nível das regularidades discursivas (FOUCAULT, 2000, p. 217, grifo do autor).

As práticas do olhar e representar o espaço levam, então, a uma forma específica de operações, maneiras de fazer (CERTEAU, 2007). Isso significa que o espaço é, em si, uma representação - um traçado é uma representação, não é o espaço; o mapa não é o território. Isso significa conceber o espaço como representação, mas não no sentido de cópia, de equivalência, mas como representação de um modo de experimentar, de saber e de olhar, bem como, de um modo de representar.

No caso do espaço militarizado, ele passa a existir como forma figurada e se torna realidade quando aquilo que é idealizado se torna experimentado e usado. Por outro lado, o acesso aos saberes matemáticos, particularmente a geometria como método de cognição da natureza e como fundamento da atividade humana, permitiu intelectualizar e gerar novas formas de espacialização.

Ao abordarmos o olhar geometrizado, na perspectiva deste estudo, remetemos aos olhos do poder, ao olhar disciplinar, esquadrinhado e panóptico, 
próprio dos regimes de governo do século XVIII. Em Vigiar e Punir, Foucault (1989) aponta para uma microfísica do poder. Isso significa que o poder não é algo que se adquire ou se detém, ele vem de toda parte, engloba tudo. O poder disciplinar, por exemplo, não é aplicado apenas aos corpos dos indivíduos, mas ao panoptismo. Assim, aquele que está sujeito a um campo de visibilidade, e sabendo que está, toma a seu encargo os constrangimentos do poder, ele os aciona espontaneamente sobre si mesmo, e se torna princípio de sua própria sujeição.

Neste âmbito teórico-metodológico a iconografia é tida como fonte de problemática de cultura visual. Neste caso, a atenção deve se deslocar, como afirma Meneses (2003), das fontes visuais para a da visualidade como objeto detentor de historicidade, e como plataforma estratégica de interesse cognitivo. Isso significa não incidir na utilização preponderante da fonte visual como mero depositório especular de informação empírica, nem mesmo na análise da dependência de técnicas de leitura derivadas de uma submissão mecânica à Iconografia/Iconologia de Panofsky ou de uma semiótica a-historicizada (MENESES, 2003). Portanto, emerge de uma problemática histórica que diz respeito à produção de imagens, que instaura modos de olhar e de saber, ou seja, de uma cultura visual (GASKELL, 1992).

A propósito, por cultura visual, segundo Knauss (2006, p.106), "Pode-se caracterizar uma definição abrangente, que aproxima o conceito de cultura visual da diversidade do mundo das imagens, das representações visuais, dos processos de visualização e de modelos de visualidade". Ressaltamos que, da aplicação desta concepção teórica e metodológica, resulta a compreensão de que os saberes são constituídos, e não só representados, em meio a práticas, experiências e problemáticas que uma sociedade se impõe como verdades e normas sociais, políticas e culturais.

Enfim, analisar as plantas e tratados militares permite-nos uma articulação com a pesquisa arqueológica e a pesquisa da cultura visual, dirigida à análise da imagem como representação visual, ou melhor, de práticas de olhar que se dão como resultado de processos de produção de sentido, em contextos culturais diversos. O pressuposto é de que o valor estético, teórico, visual, representativo das imagens é uma construção social, cultural e, especialmente, política. Assim, a imagem é o efeito e o suporte para um modo de olhar. De um lado a imagem como efeito, resultante de uma prática do olhar que tudo controla, mede, geometriza. E, por outro, como suporte para a estetização de um olhar. 


\section{Modificações}

No sul do que hoje denominamos de Estados Unidos da América, na região da Florida, na cidade de St Augustine, foi fundada uma colônia espanhola, em 1565, a qual foi denominada de San Agustin. Para a defesa deste lugar, "Uma série de fortificações de madeira foram erguidas, mas não foram suficientes para prevenir ataques de forças militares estrangeiras ou de piratas" (QUESADA, 2010, p. 6, tradução nossa). Era preciso, portanto, empreender um sistema de fortificação condizente com a atualidade e necessidade da guerra daquela época.

Em 1668, a Rainha Mariana, da Espanha, ordenou uma construção de alvenaria no lugar daquilo que era o sistema fortificado de San Agustin, construído em madeira, passando a ser, em 1672, uma fortaleza denominada de Castillo de San Marcos. Esta fortificação espanhola "[...] foi desenhada para acomodar aproximadamente cinquenta armas e foi construída de coquina, uma pedra local macia, de origem marítima, com surpreendente durabilidade e resistência aos tiros de canhão" (LEWIS, 1993, p.15, tradução nossa). A planta desta fortificação foi desenhada, basicamente, em formato quadrangular, com um grande bastião saliente, angular, em cada um dos quatro cantos (Figura 1).

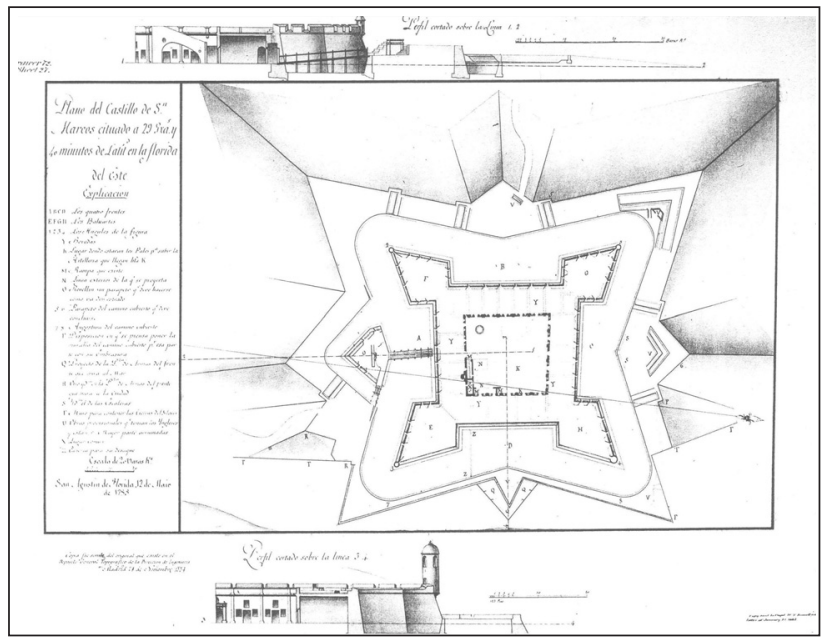

Figura 1 - Castillo de San Marcos, Florida (1672-1756). National Archives, Washington, D. C.

Fonte: Robinson (1977) 
As mudanças nas fortificações, além de se deverem à necessidade de proteção e garantia de terras conquistadas por um ou outro povoamento, também se deveram a outros fatores. Segundo Marten (2009) há três importantes fatores culturais que conduziram às mudanças nos sistemas de fortificações. $\mathrm{O}$ primeiro diz respeito à forma moderna de impressão de livros gerada por Gutenberg, no século XV, permitindo a impressão e a circulação de muitos livros, e divulgando ampla e rapidamente os conhecimentos, sobretudo acerca da geometria. Segundo Marten (2009, p. 326, tradução nossa) "Os Elementos de Euclides foi o primeiro livro a ser publicado e amplamente disponível fora dos limites das bibliotecas dos mosteiros e bibliotecas particulares de alguns estudiosos particulares". $\mathrm{O}$ segundo elemento refere-se à invenção e o desenvolvimento de técnicas de desenho, notadamente da técnica da perspectiva durante o século $\mathrm{XV}$, permitindo novas formas de representar e de se relacionar com o espaço, o real e o representado. E, por fim, “[...] a redescoberta da filosofia de Platão parece ter forçado a introdução e transmissão de formas geométricas em artes aplicadas e arquitetura" (MARTEN, 2009, p. 326, tradução nossa).

Os polígonos regulares, como o quadrado, eram formas recorrentes nas planimetrias da arquitetura militar no século XV e XVI, por possibilitarem uma forma mais proporcionada para as realizações arquitetônicas. Embora na Idade Média tenha sido usado o quadrado para desenhar algumas fortificações, com base na geometria de figuras simples, é somente a partir do Renascimento que se utiliza uma proporção baseada na relação aritmética entre os números. Portanto, segundo Costa e Sousa (2008), a geometria e a matemática tanto desenvolveram um papel importante neste processo de mudança, quanto foram fundamentais para o desenvolvimento do conhecimento militar durante o século XVI.

Os conhecimentos de geometria passaram a funcionar como uma conexão entre prática e teoria. De um lado, sua aplicação prática no campo das medidas, e de outro, e através da tradicional literatura, como fundamento para a atividade do pensamento, da razão humana. Em ambos os casos, a geometria funcionava como um método de cognição e de conhecimento da natureza, do campo de batalha, do espaço fortificado.

Contudo, naquela época, outro fato importante e fundamental que influenciou as modificações nas construções de fortificações está relacionado à artilharia. A modernização dos canhões, das armas de fogo, permitindo um alcance maior dos projéteis, impulsionou alterações importantes nas projeções e plantas das fortalezas. Dentre elas, o desenho de fortificações com baluartes angulares 
(Figura 2) e não mais circulares. Isso tem relação direta com o estudo dos ângulos dos tiros e das linhas de fogo da artilharia. O baluarte angular é subordinado a linhas de direção convergentes num ponto de fuga. Essas linhas são correspondentes às trajetórias dos tiros da artilharia cujo ponto de fuga é o inimigo (Figura 3).

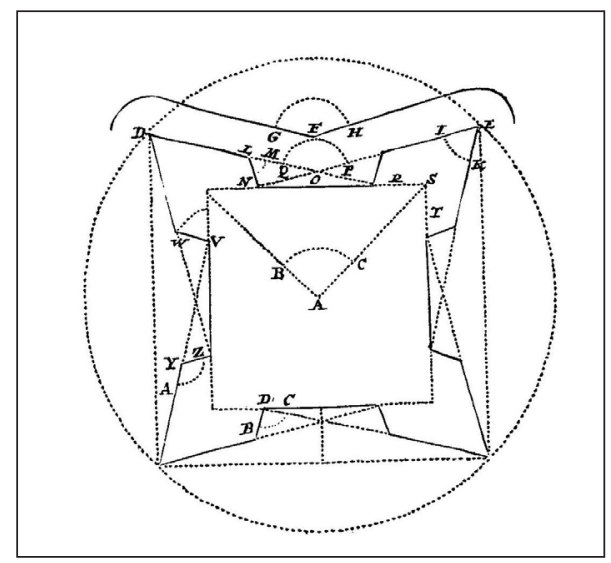

Figura 2 - Traçado de uma fortificação quadrangular com baluartes angulares Fonte: Vauban (1762)

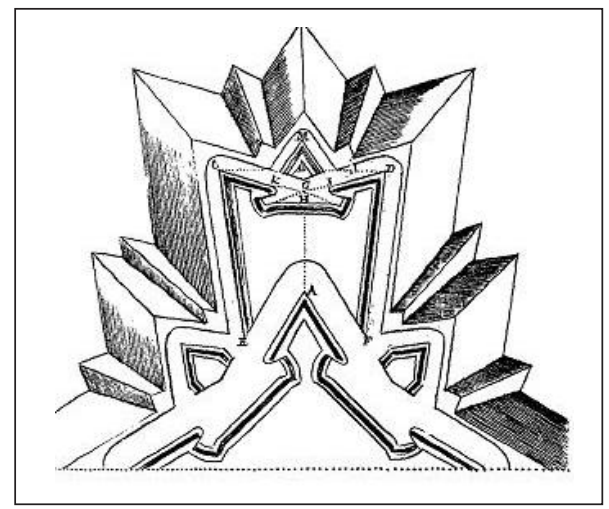

Figura 3 - Traçado das trajetórias dos tiros nos baluartes Fonte: Vauban (1762)

Assim, a técnica da perspectiva era tida não só como um meio técnico para apresentar no papel os aspectos funcionais do sistema de fortificação, mas 
como prática dos movimentos necessários ao combate, à guerra. Como um todo, o desenho em perspectiva se constituía num instrumento de maior credibilidade, de segurança, pois se acreditava que a aplicação objetiva de métodos matemáticos conferia mais segurança à realização de estratégias e cálculos de ataques, do que os desenhos bidimensionais feitos à mão livre.

Enfim, nota-se que "A radical mudança na arquitetura militar também tem sido relacionada com as mudanças no processo do desenho, que passou a incluir o momento do movimento: o desenho das linhas eram contemporaneamente linhas de movimento porque elas foram identificadas como linhas de fogo [...]" (MARTEN, 2009, p. 327, tradução nossa).

Notemos, portanto, que estas novas formas e maneiras de fortificar têm como base a utilização da geometria, por meio de métodos de construção de figuras poligonais regulares. Isso implicava conceitos matemáticos de harmonia, de proporcionalidade, que se traduziam pelas medidas simples relacionadas entre si. Porém, não só conceitos básicos de geometria eram empregados, o uso das formas e das proporções era a base para a realização de novas fortificações, mas, também, o recurso aos princípios da perspectiva, dado que o estudo das linhas de fogo é feito a partir da utilização de um ponto de fuga.

O método do desenho em perspectiva transformou-se num instrumento essencial para a cultura figurativa, a partir do século XV. Isso gerou uma nova percepção e representação do espaço. Estas duas novas situações, a primeira ao nível da percepção e concepção de espaço, a segunda relacionada às técnicas de representação gráfica, possibilitaram ultrapassar definitivamente a dimensão bidimensional, ainda presente na arte do Gótico. Portanto, conduziu a uma nova prática do olhar, passível de encontrar e criar harmonia e organização em tudo, geometrizando o espaço. O espaço tornou-se a projeção desta prática de olhar.

\section{0 pentágono}

A técnica da perspectiva era utilizada não só como um recurso na construção de figuras no plano gráfico, e para a representação das trajetórias dos tiros, mas, também, como forma de representação geral e alcance do espaço. Tornou-se comum nos diversos tratados sobre como fortificar uma vila e, consequentemente, na prática do engenheiro militar, a representação da fortificação como figura tridimensional (Figura 4), fornecendo uma imagem em relevo e em relação ao espaço onde ela seria construída. 


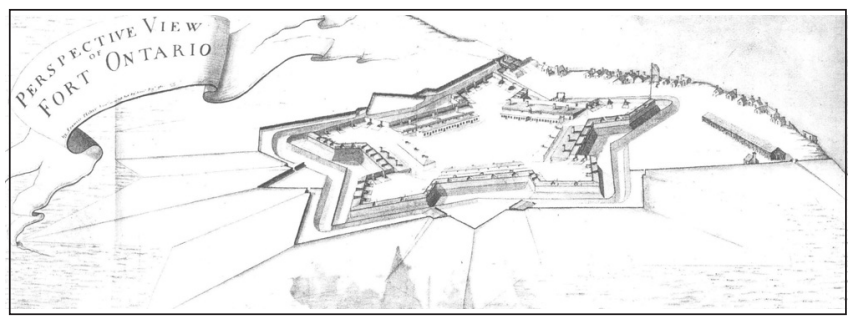

Figura 4 - Fort Ontario, New York (1759-63). Thomas Sowers, engenheiro. Vista em perspectiva (1761) por Francis Pfister

Fonte: Robinson (1977)

De fundamental importância, nos desenhos em perspectiva, é a representação visual. Primeiro, porque pegando a vantagem da vista dos olhos dos pássaros, tais desenhos forneciam uma melhor imagem da complexidade das fortalezas e da sua extensão com o ambiente. Depois, os desenhos das perspectivas vistas de cima (planos) e das vistas em perfis (Fig.5), permitiam a realização de cálculos tais como de áreas, volumes, distâncias, bem como, informavam a função das diferentes partes da fortificação e sua interação com os arredores topográficos. Logo, na experiência com estas novas imagens, "Uma nova sensibilidade do espaço e do território foi criada." (MARTEN, 2009, p.327, tradução nossa).

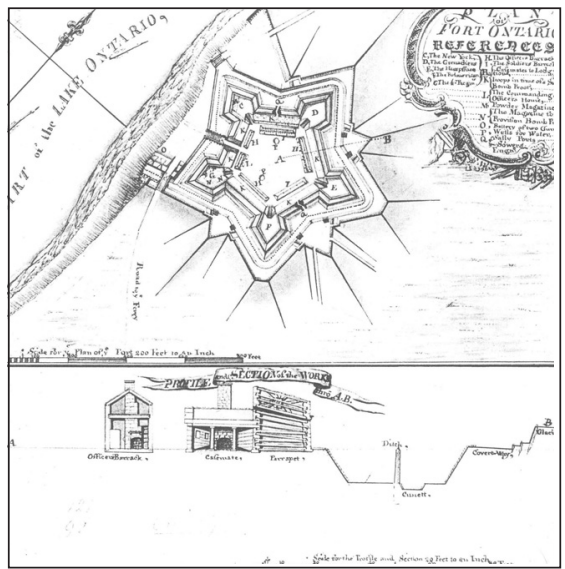

Figura 5 - Fort Ontario, New York (1759-63). Thomas Sowers, engenheiro. Plano desenhado pelo engenheiro (1759)

Fonte: Robinson (1977) 
Cabe-nos voltar a discutir sobre a forma geométrica empregada para desenhar e construir a fortificação. Se as formas regulares, preferencialmente o quadrado, eram empregadas por razões diversas, tais como a harmonia, simetria, outras formas regulares também eram empregadas pelos mesmos motivos. $\mathrm{O}$ sistema, fortificado a partir de quatro baluartes, normalmente, se constituía numa fortaleza pequena, comportando uma quantidade menor de homens. Se havia necessidade de aumentar os lados do sistema de defesa, para comportar um maior número de homens dentro da fortaleza, então, um traçado baseado em pentágono ou hexágono era requerido. Além disso, segundo Robinson (1977), o pentágono era facilmente adaptado, em terras americanas, quando se queria proteger a área entre dois rios.

O Forte Ontario (Figuras 4 e 5) é um exemplo do emprego do sistema bastionado com cinco pontas. Trata-se de uma fortaleza britânica, construída a partir de 1759, no lugar onde já houvera uma fortificação, destruída pelos franceses em 1756. A nova fortaleza foi projetada a partir de ensinamentos e recentes tecnologias européias, sendo concebida para suportar 500 homens.

A concepção de fortificação, acerca de uma variação de polígonos para desenhar, no plano, cidades ideais, geometrizadas, fazia parte de muitos tratados europeus sobre como fortificar uma vila. Segundo Kruft (1994) toda a engenharia militar na Europa do século XVII baseara-se numa concepção geométrica, harmônica e perspectivada do espaço e, particularmente, o engenheiro militar, francês, Sébastian Le Preste de Vauban foi quem, notadamente, exercera influencia na prática dos engenheiros e arquitetos militares. Os novos ensinamentos sobre como fortificar uma vila com traços regulares, pela geometria, foram ensinados e, portanto, aprendidos, por meio do tratado do Vauban, originalmente em francês, Manière de fortifies selon la méthode de monsieur de Vauban, avec um traitè preliminaire des príncipes de géométrie, publicado em Paris, em 1681, ou na versão inglesa, publicado em Londres, em 1762.

A regularidade geométrica é demonstrada no tratado do Vauban, com todos os ensinamentos da geometria necessários ao engenheiro militar. Particularmente, para o caso do pentágono (Figura 6), exemplificado pelo Forte Ontario, o traçado pentagonal se dá a partir de uma circunferência, dividida em 5 partes, cujos ângulos e simetrias revelam-se cuidadosamente calculados. 


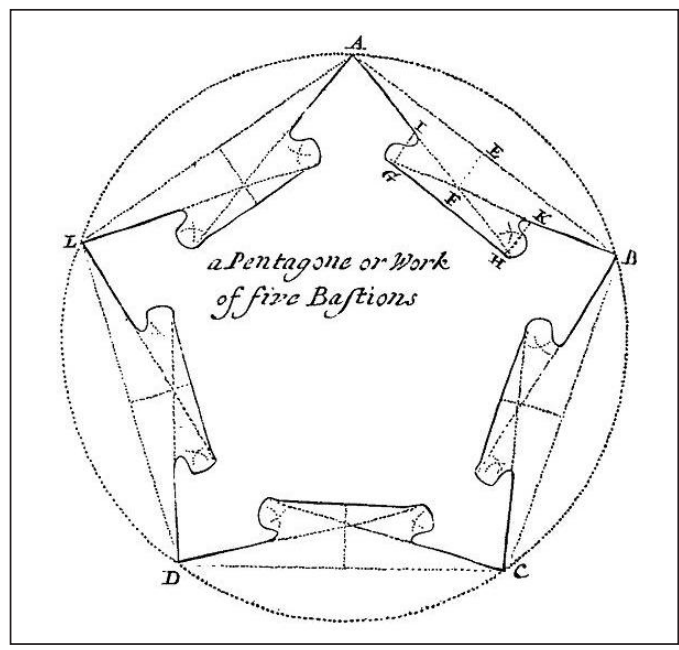

Figura 6 - Desenho de uma fortificação bastionada com cinco pontas Fonte: Vauban (1762)

O fato é que a educação aristocrática daquela época era fundada nos conhecimentos matemáticos, geométricos e saberes para fortificar uma vila. $\mathrm{O}$ alcance da performance intelectual e a autoridade dos métodos matemáticos, geométricos e da técnica da perspectiva, relacionados com fortificações, ganharam relevância social e importância, a tal ponto de constituírem um novo regime de pensamento, um regime militar de geometrizar e organizar espaço.

Com a circulação dos novos conhecimentos geométricos e das técnicas de representar, as novas regras para construir fortificações passaram a ser colocadas em prática, cada vez mais, tanto no papel, quanto em sua realização. Ainda que a topologia local fosse, ou não, tão adequada à construção de uma fortaleza, o engenheiro militar buscava adequar ao território tanto formas simétricas e regulares, quanto formas irregulares, mas geometricamente organizadas. O olhar não parou mais de geometrizar o espaço.

\section{Ressonâncias}

A iconografia militar serviu, aqui, como uma sugestão de trabalho que pode desvelar como as imagens desempenharam e desempenham um papel na construção geométrica do olhar. A utilização de uma mesma forma geométrica, em contextos culturais distintos, seja na arte militar, na arte plástica, na arquitetura, 
permite-nos notar que a imagem se constitui como representação visual e como resultado de processos de produção de sentido em contextos culturais diversos.

Baseados nisto, sugerimos que um modo de olhar se formou no âmbito das práticas militares, durante os séculos XVI e XVII. Um olhar que prega na imagem e busca, na própria realidade a organização, a simetria e a regularidade geométrica do espaço geográfico. Portanto, para olharmos as plantas militares, os projetos arquitetônicos, é preciso ter apreendido o modo desse olhar. É preciso compreender que há um modo de olhar construído para geometrizar as representações e os espaços. E que esta construção se deu a partir do aprendizado de saberes matemáticos, geométricos e da prática da técnica da perspectiva. Desenhar em perspectiva significa apreender conceitos de harmonia, paralelismo, simetria, proporcionalidade.

Isto repercute na educação matemática, no mínimo, acerca da visualização matemática e sobre as dificuldades encontradas para resolver tarefas visuais em geometria. Se há, em nossa educação, uma maneira de olhar constituída há muito tempo atrás, então, nós criamos um hábito de olhar, o qual está tão fortemente incutido em nossas práticas visuais que temos a tendência de ver regularidade, harmonia, simetria e formas geométricas simples em toda atividade que nos é oferecida. Compreender esta formatação do olhar pode contribuir com as pesquisas acerca da visualização, do ensino e da aprendizagem matemática, fornecendo pistas para a elaboração de propostas didáticas a ser desenvolvidas em sala de aula.

Enfim, saber, olhar e representar se envolveram nesta discussão não só para percebermos a circulação de saberes militares, geométricos e matemáticos, mas, sobretudo, para salientar o papel estético das formas geométricas veiculadas e difundidas pela iconografia militar dos séculos XVII e XVIII, colonizando nosso olhar geométrico. Discutir sobre como nosso olhar foi educado para formatar, regularizar geometrizar, e como nossas formas de representar não são naturais, antes, são naturalizadas, resultantes de uma prática constante e insistente em diversas áreas de conhecimento, pode conduzir à discussão sobre as crenças e atitudes dos professores em relação à matemática. Como dizem Charalambous, Panaoura e Philippou (2008), tal discussão consiste numa peça importante para qualquer que seja a abordagem instrucional dirigida à formação de professores.

Por fim, ressaltamos que um conhecimento matemático aplicado a uma prática histórica pode ser um exercício, na formação de professores, para desenvolver atividades de visualização no ensino da matemática. 


\section{Referências}

ARCAVI, A. The role of visual representations in the learning of mathematics. Educational Studies in Mathematics, Netherlands, v. 52, n. 3, p. 215 - 241, 2003.

BKOUCHE, R. Epistémologie, Histoire et enseignement des mathématiques. For the Learning of Mathematics, vol.17, n. 1, p. 34 - 42, 1997.

BORBA, M. C.; VILLARREAL, M. E. Humans-with-media and the reorganization of mathematical thinking. Information and Communication Technologies, Modeling, Visualization and Experimentation. United States of America: Springer, 2005.

CAVALCA, A. P. V. Espaço e representação gráfica: visualização e interpretação. São Paulo: Educ, 1998.

CERTEAU, M. A invenção do cotidiano: artes de fazer. 13. ed. Tradução de E. F. Alves. Petrópolis, RJ: Vozes, 2007.

CHARALAMBOS, Y. C.; PANAOURA, A.; PHILIPPOU, G. Using the history of mathematics to induce changes in preservice teachers' beliefs and attitudes: insights from evaluating a teacher education program. Educational Studies Mathematics, Netherlands, v. 71, p. 161 - 180, 2008.

COSTA E SOUSA, L. Arte na Guerra. A arquitetura dos Campos de Batalha no Portugal de Quinhentos. Lisboa: Tribuna da História Edição de Livros e Revistas, 2008.

DUVAL, R. A cognitive analysis of problems of comprehension in a learning of mathematics. Educational Studies in Mathematics, Netherlands, v. 61, n. 1 - 2, p. 103 131, Feb. 2006.

FLORES, C. Olhar, Saber, Representar: sobre a representação em perspectiva. São Paulo: Musa Editora, 2007.

FOUCAUlT, M. Vigiar e Punir. Nascimento da prisão. Tradução de L. M. P. Vassalo. 7. ed. Petrópolis: Vozes, 1989.

FOUCAULT, M. A arqueologia do saber. Tradução de L. F. Neves. 6. ed. Rio de Janeiro: Forense Universitária, 2000.

GAL, H.; LINCHEVSKI, L. To see or not to see: analyzing difficulties in geometry from the perspective of visual perception. Educational Studies Mathematics, Netherlands, v. 74, n. 2, p.163 - 183, June. 2010. 
GARDEREN, D. V. Spatial Visualization, Visual Imagery, and Mathematical Problem Solving of Students With Varying Abilities. Journal Learning Disabilities, v. 39, n. 6, p. $496-506,2006$.

GASKELL, I. História das imagens. In: BURKE, P.(Org.). A Escrita da História: novas perspectivas. Tradução de M. Lopes. São Paulo: Editora da Universidade Paulista, 1992.

KNAUSS. P. O desafio de fazer História com imagens: arte e cultura visual. Revista do Instituto de História da Universidade Federal de Uberlândia, Uberlândia, v. 8, n.12, p. 97 - 115, 2006.

KRUFT, H. W. A History of Architectural Theory: from Vitruvius to the present. New York: Princeton Architectural Presses, 1994.

LEIVAS, J. C. Imaginação, Intuição e Visualização: Possibilidades da Abordagem Geométrica no Currículo de Cursos de Licenciatura de Matemática. 2009. 294f. Tese (Doutorado em Educação) - Universidade Federal do Paraná, Curitiba, 2009.

LEWIS, E. R. Seacoast Fortifications of the United States: An Introductory History. Annapolis, Maryland: Naval Institute Press, 1993.

MARTEN, B. Fortification in Focus - Mathematical Methods in Military Architecture of the $16^{\text {th }}$ and $17^{\text {th }}$ Centuries and their Sublimation in Civil Architecture. Nexus Network Journal, Turin, v. 11, n. 2, p. 325 - 328. 2009.

MENESES, U. T. B. Fontes visuais, cultura visual, História visual. Balanço provisório, propostas cautelares. Revista Brasileira de História. São Paulo, v. 23, n. 45, p. 11 - 36. 2003.

NEMIROVSKY, R.; TIERNEY, C. Children creating ways to represent changing situations: on the development of homogeneous spaces. Educação Matemática Pesquisa, São Paulo, v. 6, n. 1, p. 11 - 5, 2004.

PRESMEG, N. Research on Visualization in Learning an Teaching Mathematics. In: GUTIERREZ, A.; BOERO, P(Eds). Handbook of Research on the Psychology of Mathematics Education: Past, Present and Future. The Netherlands: Sense Publishers, 2006. p. $205-235$.

QUESADA, A. Spanish Colonial Fortifications in North America, 1565-1822. Oxord, UK: Osprey Publishing Limited, 2010. 
ROBINSON, W. B. American Forts: architectural form and function. Fort Worth, Texas: Amon Carter Museum of Western Art, 1977.

SÁENZ-LUDLOW, A.; PRESMEG, N. Semiotic perspectives on learning mathematics and commucating mathematically. Educational Studies in Mathematics, Netherlands, v. 61, n. 6, p. 1 - 10. 2006.

TARTRE, L. A. Spatial Orientation Skill and Mathematical Problem Solving. Journal for Research in Mathematics Education, Reston, v. 21, n. 3, p. 216 - 229, May. 1990.

VAUBAN, S. L. P. The new method of fortification, as practised by Monsieur de Vauban, Engineer-General of France. 6. ed. London: C. Hitch and L. Hawes, 1762.

Submetido em Agosto de 2010. Aprovado em novembro de 2010. 


\section{ACTA SCIENTIAE}

Revista de Ensino de Ciências e Matemática

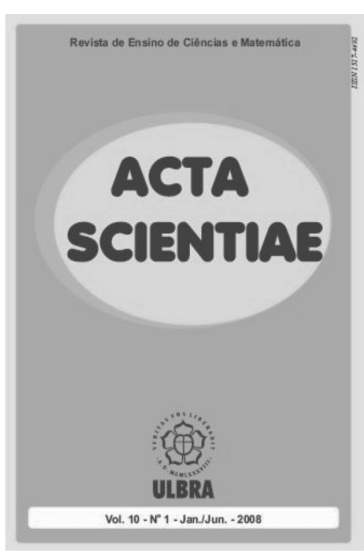

A Revista Acta Scientiae teve sua origem em 1999, mediante publicação de artigos oriundos dos pesquisadores das áreas de Ciências Naturais e Exatas da Universidade Luterana do Brasil - ULBRA Canoas (RS). Com sua indexação junto ao IBICT - Instituto Brasileiro de Informação em Ciência e Tecnologia (ISSN no. 1517-4492), é reconhecida como um espaço de publicação tanto de Ciências e Matemática como de Ensino dessas áreas. Entretanto, a partir do Volume 7, Número 1, 2005, Jan-Jun, a revista passa a publicar artigos exclusivos da área de Ensino de Ciências e Matemática, sendo editada desde sua fundação em dois números anuais. Assim, constitui-se em mais uma opção para publicação de artigos científicos dessa região de inquérito.

Confira:

http://www.ulbra.br/actascientiae

Você poderá realizar download dos exemplares da revista, encontrará informações para submissão e avaliação dos artigos.

\section{Atenção!}

A Revista Acta Scientiae é de fluxo contínuo para o recebimento de artigos. Além disso, ela é uma revista de divulgação impressa e online.

Informações:

mauriciomatematica@gmail.com

actascientiae@ulbra.br 